\title{
Episiotomy and Instrumental Delivery: Can Severe Perineal Injury Be Avoided?
}

\author{
H. Mastoroudes ${ }^{1}$, M. Gorti ${ }^{1}$ and G. Hudelist ${ }^{*}, 1,2$ \\ ${ }^{1}$ Department of Obstetrics and Gynaecology, Worthing Hospital, UK \\ ${ }^{2}$ Department of Obstetrics and Gynaecology, Division of Special Gynaecology, University of Vienna Medical Center, \\ Austria
}

\begin{abstract}
Third degree perineal tears are a major complication in vaginal childbirth and are more frequent in vaginal operative deliveries (VOD). Several studies have reported on risk factors associated with severe perineal trauma and its complications such as fecal and urinary incontinence. Within this, the role performance and type of episiotomy remains controversial, especially if combined with VOD. Although midline and mediolateral episiotomies are commonly performed in combination with VOD, their role for prevention of severe perineal trauma in VOD is still unclear. In order to elucidate the impact of midline and mediolateral episiotomy in conjunction with VOD, the present review focuses on the potential risks and benefits of these episiotomy types and their role in VOD.
\end{abstract}

Speciality: Obstetrics

Essence: Observational studies suggest that mediolateral episiotomy should be the preferred method to reduce the incidence of severe perineal trauma if instruments, especially forceps are used for VOD. Midline episiotomies should be avoided in combination with VOD as they appear to substantially increase the risk for sphincter disruption.

\section{INTRODUCTION}

Severe perineal laceration, i.e. partial or complete rupture of the external anal sphincter muscle is regarded as a major complication of vaginal childbirth. Although primary surgical repair of the external sphincter muscle performed immediately after delivery has been associated with a favorable outcome in various studies [1-3], long term complications may occur including anal incontinence, urinary incontinence, pelvic floor defects, dyspareunia, increase in need for analgesics, sexual dysfunction and finally depression [4-7]. However, it should be noted that anorectal complaint does not appear to be a rare event in patients undergoing vaginal birth since up to $10 \%$ of all women are reported to suffer from defecatory symptoms following spontaneous vaginal delivery (SVD) and between $13 \%$ and $20 \%$ experience transient flatus incontinence [8-10]. Several follow-up studies on the outcome of perineal trauma involving the external sphincter indicate that fecal incontinence may develop in 29 to $57 \%$ of patients $[5,8,11,12]$. As a consequence, recognition of risk factors and preventive measures to avoid severe perineal trauma and associated complications have been discussed by obstetricians for several decades. Numerous studies have evaluated independent risk factors for severe perineal damage secondary to childbirth. In principle, 2 groups of factors influencing the risk for occurrence of severe perineal trauma have been identified: those that are pre-defined, such as birth weight, parity, maternal age, race and fetal position/ presentation [13-15]. On the other hand, factors which can be modified by clinicians in order to improve patient care and outcome involve performance and type of episiotomy and the performance vaginal operative deliveries (VOD). The present review will focus on the occurrence of severe

*Address correspondence to this author at the Department of Obstetrics and Gynaecology, Division of Special Gynaecology, University of Vienna Medical Center, Austria; E-mail: gernot_hudelist@yahoo.de perineal tears in association with VOD and the role of episiotomy for prevention of third or fourth degree perineal damage if routinely combined with instrumental delivery.

\section{DIAGNOSIS AND COMPLICATIONS OF PERINEAL TRAUMA}

Per definition, severe perineal damage, i.e. third or fourth degree perineal injury includes partial or complete disruption of the external and/or internal anal sphincter involving the rectal mucosa in case of fourth degree tears. However, comparison of rates of severe perineal injuries between different institutions must be done with caution since there are various approaches for diagnosis for external anal sphincter damage. Clinical examination of the perineum involves visualization of the circular fibres of the external sphincter and is considered the standard method of identifying severe perineal tears. However, Andrews et al. [14] demonstrated that a significant proportion of clinicians do not accurately identify anal sphincter injuries. According to his observations, $87 \%$ of severe perineal tears were missed by midwives and approximately $24 \%$ could not be identified adequately by doctors, suggesting that a considerable proportion of severe perineal tears are misdiagnosed and consequently repaired inappropriately therefore leading to both, short and long term complications. Interestingly, the number of diagnosed events of severe perineal trauma appears to rise when rectal sonography is used for detection of perineal tears. Again, criteria for diagnosis are not uniform and tend to vary between investigators due to the complexity of the anal sphincter anatomy and associated appearance of anatomical structures on the scan images. Different groups have looked at various parameters including continuity and width of internal and external sphincter fibres and its association with evident sphincter damage which has lead to sonographic grading of the degree of evident sphincter disruption. For example, Voyvodic and colleagues [16] divided the degree of perineal tears on the presence or absence of more or less than 25 percent circumferential involvement. A different method is sug- 
gested by Starck et al. [17] who implemented a score of 1-16 for minor to major damage of the external sphincter based on the sonographic appearance of muscle fibres. Whether the use routine use of sonography for detection of severe perineal trauma is truly superior to clinical diagnosis of sphincter disruption in everyday clinical practice is a subject of constant debate. Within this, Faltin et al. [18] aimed to diagnose anal sphincter injury post partum with both methods in order to determine clinical implications such as future faecal incontinence in a randomised control trial involving 752 primiparous women. Clinically undetected tears of the anal sphincter were diagnosed by rectal sonography in 42 of 150 women $(28 \%)$ investigated and would have to be performed routinely in 29 women to prevent 1 case of severe faecal incontinence.

\section{EPISIOTOMY - A RISK FACTOR FOR SEVERE PER- INEAL TRAUMA?}

Over decades, episiotomies have routinely been performed to prevent severe perineal damage. However, in the light of recent studies and reviews on the preventive role of episiotomy for avoidance of perineal trauma in vaginal childbirth, its preventative role is highly questionable and is in some countries rather based on tradition than on good evidence. Until to date, the type and use of episiotomy for avoidance of perineal trauma in spontaneous vaginal childbirth remains controversial. Within this, Angioli et al. [6] reviewed a total of 50210 vaginal deliveries concluding that the episiotomy procedure per se, regardless of the type of episiotomy used, represents an independent risk factor for sphincter disruption. Bek et al. [19], Bodner et al. [20] and Bodner-Adler and colleagues [21] also found an increased risk of anal sphincter tear when mediolateral episiotomy was used. By contrast, Poen et al. [22], Shiono et al. [23] and de Leeuw et al. [2] showed that mediolateral episiotomy was protective against anal sphincter damage and fecal incontinence after vaginal delivery, whereas Hendriksen and coworkers [24] and Buekens et al. [25] found no association between mediolateral episiotomy and lesions of the anal sphincter.

Vaginal operative delivery, i.e. the use of forceps or vacuum extraction (VE) to facilitate and assist vaginal childbirth is regarded an independent risk factor for severe perineal trauma $[6,14,21,26]$. As a consequence, the use of these instruments is often combined with episiotomy in order to avoid sphincter damage by reducing tension on the perineum and guiding the localization and direction of the perineal and/or vaginal laceration. However, delivery details such as the type of instrument used for assisted vaginal delivery and/or the use and type of episiotomy greatly varies between European and American clinics and therefore have to be taken into account when discussing the subject. In general, American obstetricians tend to advocate forceps over vacuum extractors and prefer midline episiotomy over mediolateral episiotomy. In contrast, the instrument of choice in most European countries is the vacuum extractor and mediolateral episiotomies are more widespread.

\section{MIDLINE EPISIOTOMY AND VAGINAL ASSISTED DELIVERIES}

Midline episiotomy involves a vertical incision in the direction of the anal sphincter. Although midline episiotomies have been reported to confer the advantage of minor blood loss, good tendency to heal associated with favourable outcome regarding sexual function and cosmetic appearance [7], it has been associated with a higher risk for severe perineal damage compared to mediolateral episiotomy in SVD [6, $21,27-30]$. This risk appears to be even more pronounced when midline episiotomy is combined with instrumental measures. Although there are various studies on the association of VOD, the use of episiotomy and severe perineal trauma, very few retrospective studies clearly separate the use of midline and mediolateral episiotomies in combination with $V E$ or forceps in their subgroup analyses and direct comparisons of episiotomy types and VOD is lacking. Kudish et al. [31] recently evaluated the risk of severe perineal lacerations in 33842 primiparous and multiparous women undergoing either forceps-assisted $(n=1703,5 \%)$ and VEassisted vaginal deliveries $(n=802,2.4 \%)$ in combination with midline episiotomy. Primiparous and multiparous women with undergoing forceps deliveries in combination with midline episiotomy exhibited a higher risk for severe perineal trauma $[41.8 \%$, OR 21.1; (95\% CI, 16.7-25.5); $22.2 \%$, OR 77.1 ; (95\% CI, 49.7-104.5)] compared to the use of forceps alone [23.2\%, OR 8.6; (95\%CI, 6.6-10.7), 8.5\%, OR 26.3; (95\% CI, 18.1-34.5)]. Similarly, primiparous and multiparous patients undergoing $V E$ combined with midline episiotomy [34.7\%, OR 13.7; (95\% CI, 10.1-17.3); 30.3\%, OR 123.5; (95\% CI, 71.1-175.9)] faced a higher incidence of perineal damage compared to the use of $V E$ alone [9.4\%, OR 3.1; (95\% CI, 1.9-4.3); 0.5\%, OR 1.2; (95\% CI, 0.1-2.3)]. Ecker et al. [32] investigated the association between maternal vaginal and perineal morbidity and episiotomy performed at operative vaginal delivery. Although the authors did not perform a subgroup analysis for mediolateral and midline incisions, they were able to demonstrate that a reduction in the use of episiotomy for operative vaginal deliveries was not associated with a change in the rate of thirddegree lacerations but conferred a decrease in the rate of fourth-degree lacerations. Presuming a widespread use of mediolateral episiotomies at these institutions, the study again suggests that VOD in combination of midline episiotomy is a particularly bad combination for the perineum. Further support is given by data from Nakai and colleagues [33] who retrospectively analyzed 7,946 deliveries were with 135 resulting in severe lacerations $(1.7 \%)$. Applying multivariate logistic regression analysis, severe lacerations were associated significantly with primiparity (OR 4.36; 95\% CI, 2.179.57), oxytocin use (OR 2.19; 95\% CI, 1.27-3.73), midline episiotomy (OR, 4.68; 95\% CI, 2.09-11.55), forceps-assisted delivery (OR, 7.11;95\% CI, 1.95-20.59), vacuum-assisted delivery (OR, 5.93; 95\% CI, 3.38-10.36), leading to the conclusion that midline episiotomy and assisted vaginal delivery, especially forceps-assisted delivery should be avoided especially in primiparous patients.

\section{MEDIOLATERAL EPISIOTOMY AND OPERATIVE VAGINAL DELIVERY}

Mediolateral episiotomy involves an incision starting at the fourchette aiming for an angle midway between the anus and ischial tuberosiy based on the theory that the perineal laceration caused by the mediolateral incision is less likely to extend into the area of the anal sphincter which is supported by observations of Eogan et al. [34] suggesting that for approximately every 6 degrees away from the midline an 
episiotomy was cut, the relative risk for developing a third degree tear was reduced by approximately $50 \%$ in both, unassisted and VOD. As regards to the published literature, distinctive data on the direct comparison of mediolateral episiotomy and midline in VOD is lacking. However, several lines of evidence indicate that rates of severe perineal trauma occurring with VOD are lower in institutions where exclusively mediolateral episiotomies are performed and combined with the use of instruments. In a retrospective study of 16172 primigravid vaginal deliveries conducted by Gupta et al. [35], instrumental delivery by the aid of forceps in an institution where mediolateral episiotomy is the method of choice was not found to be an independent risk factor for sphincter damage with $36(1.6 \%)$ of 2311 forceps deliveries resulting in third degree lacerations. Similarly, Sheiner et al. [15] observed a third degree tear rate of only $0.1 \%$ in over 98 000 deliveries in a university center where exclusively mediolateral episiotomies are performed. In order to investigate risk factors for severe perineal trauma and to evaluate the impact of the combination of routinely performed mediolateral episiotomy and the exclusive use of forceps in VODs, Hudelist et al. [26] clearly identified forceps delivery in routine combination with mediolateral episiotomy and birthweight as an independent risk factors for sustained third and fourth degree tears. However, the overall incidence of severe perineal tears in a study population of 5377 patients was reported $0.9 \%$ with only 14 out of $333(4.2 \%)$ patients with forceps deliveries experiencing severe perineal trauma.

\section{CONCLUSIONS}

Severe perineal trauma is regarded a major complication of vaginal childbirth, especially when instruments such as forceps or $V E$ is used to assist vaginal delivery of the infant. Although VOD is rarely used without previously incising the perineum, studies clearly addressing the role of midline $v s$ mediolateral episiotomies in combination with VOD are surprisingly sparse with direct comparisons of the two methods lacking. Although available data are retrospective and do not provide a 2-armed design, the majority of the observational studies suggest that mediolateral episiotomy should be the preferred method to reduce the incidence of severe perineal trauma if instruments, especially forceps are used for VOD. Midline episiotomies should be avoided in combination with VOD as they appear to substantially increase the risk for sphincter disruption.

\section{REFERENCES}

[1] Barter RH, Parks J, Tyndal C. Median episiotomies and complete perineal lacerations. Am J Obstet Gynecol 1960; 80: 654-662.

[2] De Leeuw JW, Vierhout ME, Struijk PC, Hop WC, Wallenburg HC. Anal sphincter damage after vaginal delivery: functional outcome and risk factors for fecal incontinence. Acta Obstet Gynecol Scand 2001; 80(9): 830-834.

[3] Sieber EH, Kroon JD. Morbidity in the third-degree laceration. Obstet Gynecol 1962; 19: 677-680.

[4] Carley ME, Carley JM, Vasdev G, et al. Factors that are associated with clinically overt postpartum urinary retention after vaginal delivery. Am J Obstet Gynecol 2002; 187(2): 430-433.

[5] Combs CA, Robertson PA, Laros RK Jr. Risk factors for thirddegree and fourth-degree perineal lacerations in forceps and vacuum deliveries. Am J Obstet Gynecol 1990; 163(1 Pt 1): 100-104.

[6] Angioli R, Gomez-Marin O, Cantuaria G, O'Sullivan M J. Severe perineal lacerations during vaginal delivery: the University of Miami experience. Am J Obstet Gynecol 2000; 182(5): 1083-1085.

[7] Fenner DE, Genberg B, Brahma P, Marek L, DeLancey JO. Fecal and urinary incontinence after vaginal delivery with anal sphincter disruption in an obstetrics unit in the United States. Am J Obstet Gynecol 2003; 189(6): 1543-1549; discussion 1549-1550.

[8] Sultan AH, Kamm MA, Hudson CN, Bartram CI. Third degree obstetric anal sphincter tears: risk factors and outcome of primary repair. Bmj 1994; 308(6933): 887-891.

[9] Signorello LB, Harlow BL, Chekos AK, Repke JT. Midline episiotomy and anal incontinence: retrospective cohort study. Bmj 2000; 320(7227): 86-90.

[10] Chaliha C, Sultan AH, Bland JM, Monga AK, Stanton SL. Anal function: effect of pregnancy and delivery. Am J Obstet Gynecol 2001; 185(2): 427-432.

[11] Haadem K, Dahlstrom JA, Lingman G. Anal sphincter function after delivery: a prospective study in women with sphincter rupture and controls. Eur J Obstet Gynecol Reprod Biol 1990; 35(1): 7-13.

[12] Nygaard IE, Rao SS, Dawson JD. Anal incontinence after anal sphincter disruption: a 30-year retrospective cohort study. Obstet Gynecol 1997; 89(6): 896-901.

[13] Aukee P, Sundstrom H, Kairaluoma MV. The role of mediolateral episiotomy during labour: analysis of risk factors for obstetric anal sphincter tears. Acta Obstet Gynecol Scand 2006; 85(7): 856-860.

[14] Andrews V, Sultan AH, Thakar R, Jones PW. Risk factors for obstetric anal sphincter injury: a prospective study. Birth 2006; 33(2): 117-122.

[15] Sheiner E, Levy A, Walfisch A, Hallak M, Mazor M. Third degree perineal tears in a university medical center where midline episiotomies are not performed. Arch Gynecol Obstet 2005; 271(4): 307-310.

[16] Voyvodic FRN, Skinner S, Schloithe AC, Saccone GT, Sage MR, Wattchow DA. Endosonographic imaging of anal sphincter injury: does the size of the tear correlate with the degree of dysfunction? Dis Colon Rectum 2003; 46(6): 735-741.

[17] Starck M BM, Valentin L. Results of endosonographic imaging of theanal sphincter 2-7 days after primary repair of third- or fourthdegree obstetric sphincter tears. Ultrasound Obstet Gynecol 2003; 22(6): 609-615.

[18] Faltin DL BM, Floris LA, Irion O. Diagnosis of anal sphincter tears to prevent fecal incontinence: a randomized controlled trial. Obstet Gynecol 2005; 106(1): 6-13.

[19] Bek KM, Laurberg S. Risks of anal incontinence from subsequent vaginal delivery after a complete obstetric anal sphincter tear. Br J Obstet Gynaecol 1992; 99(9): 724-726.

[20] Bodner K, Bodner-Adler B, Wagenbichler P, et al. Perineal lacerations during spontaneous vaginal delivery. Wien Klin Wochenschr 2001; 113(19): 743-746.

[21] Bodner-Adler B, Bodner K, Kaider A, et al. Risk factors for thirddegree perineal tears in vaginal delivery, with an analysis of episiotomy types. J Reprod Med 2001; 46(8): 752-756.

[22] Poen AC, Felt-Bersma RJ, Dekker GA, Deville W, Cuesta MA, Meuwissen SG. Third degree obstetric perineal tears: risk factors and the preventive role of mediolateral episiotomy. $\mathrm{Br} \mathrm{J}$ Obstet Gynaecol 1997; 104(5): 563-566.

[23] Shiono P, Klebanoff MA, Carey JC. Midline episiotomies: more harm than good? Obstet Gynecol 1990; 75(5): 765-770.

[24] Henriksen TB, Bek KM, Hedegaard M, Secher NJ. Episiotomy and perineal lesions in spontaneous vaginal deliveries. Br J Obstet Gynaecol 1992; 99(12): 950-954.

[25] Buekens P, Lagasse R, Dramaix M, Wollast E. Episiotomy and third-degree tears. Br J Obstet Gynaecol 1985; 92(8): 820-823.

[26] Hudelist G, Gelle'n J, Singer C, et al. Factors predicting severe perineal trauma during childbirth: role of forceps delivery routinely combined with mediolateral episiotomy. Am J Obstet Gynecol 2005; 192(3): 875-881.

[27] Baumann P, Hammoud AO, McNeeley SG, Derose E, Kudish B, Hendrix S. Factors associated with anal sphincter laceration in 40,923 primiparous women. Int Urogynecol J Pelvic Floor Dysfunct 2007.

[28] Benifla JL, Abramowitz L, Sobhani I, et al. [Postpartum sphincter rupture and anal incontinence: prospective study with 259 patients] Gynecol Obstet Fertil 2000; 28(1): 15-22.

[29] Jander C, Lyrenas S. Third and fourth degree perineal tears. Predictor factors in a referral hospital. Acta Obstet Gynecol Scand 2001; 80(3): 229-234.

[30] Klein MC, Gauthier RJ, Robbins JM, et al. Relationship of episiotomy to perineal trauma and morbidity, sexual dysfunction, and pelvic floor relaxation. Am J Obstet Gynecol 1994; 171(3): 591-598. 
[31] Kudish B, Blackwell S, McNeeley SG, et al. Operative vaginal delivery and midline episiotomy: a bad combination for the perineum. Am J Obstet Gynecol 2006; 195(3): 749-754.

[32] Ecker JL, Tan WM, Bansal RK, Bishop JT, Kilpatrick SJ. Is there a benefit to episiotomy at operative vaginal delivery? Observations over ten years in a stable population. Am J Obstet Gynecol 1997; 176(2): 411-414.

[33] Nakai A, Yoshida A, Yamaguchi S, et al. Incidence and risk factors for severe perineal laceration after vaginal delivery in Japanese patients. Arch Gynecol Obstet 2006; 274(4): 222-226.
[34] Eogan M DL, O'Connell PR, O'Herlihy C. Does the angle of episiotomy affect the incidence of anal sphincter injury? $\mathrm{Br} \mathrm{J} \mathrm{Ob}-$ stet Gynaecol 2006; 556(113): 190-194.

[35] Gupta N, Kiran TU, Mulik V, Bethel J, Bhal K. The incidence, risk factors and obstetric outcome in primigravid women sustaining anal sphincter tears. Acta Obstet Gynecol Scand 2003; 82(8): 736743 . 